\title{
Healthcare Setting and Methicillin Resistant Staphylococcus aureus
}

IJCRR
Section: Healthcare
Sci. Journal Impact
Factor: $6.1(2018)$
ICV: $90.90(2018)$
Scopus

\section{Vandana Kubde', Gargi Dangre (Mudey) ${ }^{2}$, Abhay Mudey ${ }^{3}$}

Ph.D Scholar, Department of Microbiology,]awaharlal Nehru Medical College, Datta Meghe Institute of Medical Sciences, Sawangi (Meghe), Wardha Maharashtra, India; ${ }^{2}$ Professor and HOD, Department of Microbiology, Datta Meghe Medical College, Shalinitai Meghe Hospital and Research Cen-

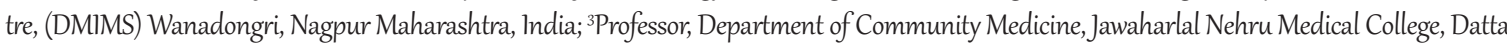
Meghe Institute of Medical Sciences, Sawangi (Meghe), Wardha Maharashtra, India.

\section{ABSTRACT}

Methicillin-resistant Staphylococcus aureus (MRSA) infection remains the ever-increasing health care problem. It brings a high rate of morbidity and mortality especially in immunocompromised and hospitalised patients. MRSA infection is most often severe due to the expression of virulence factors, toxins, and immune-modulatory gene products along with limited options for its treatment. MRSA in the healthcare settings is an emerging challenge. Exposure of healthcare personnel to the MRSA environment puts them at increased risk of acquiring the infection. Given the limited options for treatments, there is a need to cautious use the current treatments and quest for research and development of new anti-MRSA agents. For the prevention of MRSA infection in healthcare personnel, adequate implementation of infection and prevention strategies is essential in all healthcare settings. In this article, we discussed the epidemiology of MRSA, current and emerging treatment options along with infection control strategies in the healthcare settings.

Key Words: MRSA, MSSA, Antibiotic resistance, Treatment, Prevention, Epidemiology

\section{INTRODUCTION}

For many decades, Staphylococci are known to be involved in human disease. They were first isolated as causative pathogens of incurable boils. Two scientists namely, Sir Alexander Ogsto and Friedrich J. Rosenbach, contributed to the nomenclature of Staphylococci ${ }^{1}$. S. aureus has since evolved as a major infectious pathogen. It is severely detrimental to the health of millions of patients. The emergence of penicillin resistance was reported in 1942 and was due to inducible beta-lactamase. Methicillin first used in 1959, and the methicillin-resistant $S$. aureus (MRSA) was reported within two years of its approval ${ }^{2}$. MRSA is present globally and its burden in middle-income countries like India is especially high with a recent study reporting it high as $41 \%{ }^{3}$. MRSA is reported from hospital- as well as community-setting. A recent study from south India reported a prevalence of $20 \%$ and $7 \%$ being hospital-acquired MRSA (HA-MRSA) and community-acquired MRSA (CA-MRSA) ${ }^{4}$. In evaluating HCPs, a study from United Kingdom reported that among 198 healthcare workers (HCWs), 37\% were S. aureus nasal carriers and $4 \%$ among them carried $\mathrm{MRSA}^{5}$. A meta- analysis of 31 studies reported a pooled MRSA colonization rate of $1.8 \%$ with the highest colonization rate for nursing staff $(6.9 \%)^{6}$. It indicates HCP is at risk of MRSA colonization. HA-MRSA is also associated with an increased risk of mortality and poor prognosis of the patients ${ }^{7,8}$. Therefore, adequate control of MRSA in a healthcare setting is necessary to optimize patient outcomes and reduce exposure risk and colonization among HCPs.

\section{EPIDEMIOLOGY OF MRSA}

MRSA is prevalent globally. However, prevalence varies widely within different countries. The study from Europe reported MRSA incidence of $0.5 \%$ in Iceland and $44 \%$ in Greece $^{9}$. The Indian Network for Surveillance of Antimicrobial Resistance (INSAR) group reported MRSA prevalence of $41 \%$. MRSA isolated from outpatients, ward inpatients, and intensive care unit (ICU) were $28 \%, 42 \%$ and $43 \%$ in 2008 and $27 \%, 49 \%$ and $47 \%$ in $2009^{3}$. In a study by Kaiser et al., the incidence of HA-MRSA was $9 \%$ in patients with burns ${ }^{10}$. Another study from Saudi Arabia reported MRSA

\section{Corresponding Author:}

Mrs. Vandana Kubde, PhD Scholar, Department of Microbiology, Jawaharlal Nehru Medical College, Datta Meghe Institute of Medical Sciences, Sawangi (Meghe), Wardha Maharashtra

ISSN: 2231-2196 (Print) ISSN: 0975-5241 (Online)

Received: 05.06 .2020

Revised: 28.06 .2020

Accepted: 10.07 .2020

Published: 21.07 .2020 
prevalence of $38 \%{ }^{11}$. A study from Iraq in hospital staff observed $50.4 \%$ mecA gene positivity among the isolates of MRSA ${ }^{12}$. On hospital admission, a meta-analysis finds that factors such as healthcare contact, previous healthcareassociated pathogens, and comorbid conditions such as congestive heart failure, diabetes, are associated with MRSA colonization $^{13}$. Thus, early identification of MRSA isolates is essential to prevent adverse outcomes.

\section{LABORATORY METHODS FOR DIAGNOSIS OF MRSA}

The present study was conducted in the Dept. of Microbiology at Jawaharlal Nehru Medical College, Datta Meghe Institute of Medical Sciences, Sawangi, Wardha in collaboration with Datta Meghe Medical College, Nagpur. Various methods for methicillin (oxacillin) susceptibility testing include the following ${ }^{14-17}$.

- Dilution methods: Agar dilution and broth microdilution

- $\quad$ Etest method

- Breakpoint methods

- Agar screening method

- Disc diffusion

- Latex agglutination

- Automated methods: Vitek/Vitek2 (bioMe'rieux), Phoenix (Becton Dickinson) and Microscan (Dade Behring)

- Quenching fluorescence method

- Molecular methods

o Direct identification of MRSA in blood cultures

- gel-based and real-time PCR

- DNA probes

- Peptide nucleic acid probe

- EVIGENE kit: colorimetric gene probe hybridization assay for staphylococcus-specific $16 \mathrm{~S}$ rRNA, mecA and nuc gene sequences

o Identification of MRSA in endotracheal aspirates and other clinical samples

- multiplex PCR procedure (targeting the femA and $m e c A$ genes)

In addition to conventional culture, molecular methods for direct identification of MRSA are being used more commonly. The majority of PCR-methods approved by the USFDA are equivalent. Their sensitivities and specificities range from 82 to $100 \%$ and 64 to $99 \%$, respectively ${ }^{15}$. The list of currently approved PCR assays for MRSA detection is as below.

- BD GeneOhm MRSA ACP for nares

- BD Gene Ohm Staph SR for positive blood cultures

- Xpert MRSA Cepheid for nares

- Xpert SA Nasal Complete for nares

- Xpert MRSA/SA SSTI for skin and soft tissue infections
- Xpert MRSA/SA BC for positive blood cultures

- Light Cycler MRSA for nares

The use of molecular methods has the advantage of high sensitivity and rapid turnaround time. However, conventional culture methods can provide information on sensitivities. Pourmand et al. compared four different methods in the detection of MRSA. Rates of identification of MRSA was $50 \%$, $50 \%, 40 \%$, and $45.83 \%$ in mecA gene detection, cefoxitin disc diffusion test, oxacillin disc diffusion test, and MIC test strip, respectively. ${ }^{17}$

\section{TREATMENTS OF MRSA}

MRSA is associated with a wide variety of infections. Some infections such as bacteraemia, endocarditis, osteomyelitis are serious MRSA infections ${ }^{19}$. The frequency of each type of infection may vary in a hospital setting. In patients with MRSA infection, Madani TA identified surgical site infection $(31.1 \%)$ as the most common type followed by pneumonia (27\%), central venous catheter infection (13.5\%), peripheral venous line infection (6.8\%), and bacteraemia in $27 \%$ cases $^{11}$. The (INSAR) group reported the isolation of MRSA most commonly from the skin and soft tissue infection $(64 \%$ in 2008 and $61 \%$ in 2009) followed by blood (44\% in 2008 and $48 \%$ in 2009) and respiratory (44\% in 2008 and $41 \%$ in 2009) samples ${ }^{3}$. A study from South Western India reported among 284 cases with confirmed MRSA, 65\% were healthcare-associated $\mathrm{MRSA}^{20}$. Given the significant prevalence of MRSA in hospital setting, it needs to be managed effectively.

The Infectious Disease Society of America (IDSA) provides recommendations for treatment of different MRSA infections. The initial choice of antibiotics is summarized in Table $1^{21}$. It is quite clear from this table that vancomycin is the first choice in most MRSA infections. Along with vancomycin, linezolid, daptomycin, and clindamycin are also preferred agents. However, the emergence of resistance to these agents calls for their cautious use. The emergence of multidrug-resistant (MDR) MRSA with resistance to linezolid, tigecycline, and vancomycin has also been reported from India ${ }^{22}$.

\section{Table 1: Initial treatment options for MRSA infec- tions

MRSA infection Recommended treatments ${ }^{21}$ \\ Skin and skin Clindamycin, TMP-SMX, Doxycycline/ \\ structure infections Minocycline, Linezolid (1-2 weeks) (SSTIs) \\ Complicates SSTIs Vancomycin, Linezolid, Daptomycin, Telavancin, Clindamycin (1-2 weeks) \\ Bacteraemia Vancomycin, Daptomycin (2 weeks)}




\section{Table 1: (Continued)}

\begin{tabular}{|c|c|}
\hline MRSA infection & Recommended treatments ${ }^{21}$ \\
\hline $\begin{array}{l}\text { Complicated bacte- } \\
\text { raemia }\end{array}$ & Vancomycin, Daptomycin (4-6 weeks) \\
\hline \multicolumn{2}{|r|}{ Infective endocarditis } \\
\hline Native valve & Vancomycin, Daptomycin (6 weeks) \\
\hline Prosthetic valve & $\begin{array}{l}\text { Vancomycin + Rifampicin ( } 6 \text { weeks) fol- } \\
\text { lowed by Gentamicin ( } 2 \text { weeks) }\end{array}$ \\
\hline $\begin{array}{l}\text { Pneumonia: Hospi- } \\
\text { tal- or community- } \\
\text { acquired }\end{array}$ & $\begin{array}{l}\text { Vancomycin, Linezolid, Clindamycin, } \\
\text { (1-3 weeks) }\end{array}$ \\
\hline \multicolumn{2}{|c|}{ Bone and Joint Infections } \\
\hline Osteomyelitis & $\begin{array}{l}\text { Vancomycin, Daptomycin, TMP-SMX + } \\
\text { Rifampicin, Linezolid, Clindamycin ( } 8 \\
\text { weeks) }\end{array}$ \\
\hline Septic arthritis & $\begin{array}{l}\text { Vancomycin, Daptomycin, TMP-SMX + } \\
\text { Rifampicin, Linezolid, Clindamycin (3-4 } \\
\text { weeks) }\end{array}$ \\
\hline Device related & $\begin{array}{l}\text { [Vancomycin, Daptomycin, Linezolid, } \\
\text { Clindamycin] + Rifampicin ( } 2 \text { week) } \\
\text { followed by Rifampicin + [FQ, TMP- } \\
\text { SMX, Tetracycline, Clindamycin] (3-6 } \\
\text { months) }\end{array}$ \\
\hline \multicolumn{2}{|c|}{ Central Nervous System Infections } \\
\hline Meningitis & $\begin{array}{l}\text { Vancomycinwith or without Rifampicin } \\
\text { ( } 2 \text { weeks), Linezolid, TMP-SMX }\end{array}$ \\
\hline $\begin{array}{l}\text { Brain or Spinal } \\
\text { epidural abscess }\end{array}$ & $\begin{array}{l}\text { Vancomycin with or without Rifampicin } \\
\text { (4-6 weeks) Linezolid, TMP-SMX }\end{array}$ \\
\hline $\begin{array}{l}\text { Septic thrombosis } \\
\text { of sinus (dual ve- } \\
\text { nous/cavernous) }\end{array}$ & $\begin{array}{l}\text { Vancomycin with or without Rifampicin } \\
\text { (4-6 weeks) Linezolid, TMP-SMX }\end{array}$ \\
\hline
\end{tabular}

Besides the development of resistance, these initial treatments have certain limitations. Kashyap et al. in their indepth review provide the limitation of current anti-MRSA agents $^{23}$. Notably, nephrotoxicity, MIC creep phenomenon, variable tissue penetration are reported with vancomycin. Additionally, the risk of red man syndrome is associated with rapid intravenous vancomycin use. With daptomycin, there is a risk of cross-resistance with heteroresistant vancomycin intermediate resistant $S$. aureus (hVISA). It is deactivated by the pulmonary surfactant making it unsuitable for pulmonary MRSA infections. Use of linezolid has risk serious side effects such as thrombocytopenia, optic neuropathy, etc. In India, it has specific limitations as it is one of the drugs in the MDR tuberculosis regimen. Use of trimethoprim-sulfamethoxazole, tetracyclines, and clindamycin are limited by the development of significant resistance ${ }^{23}$. Thus, there is needs to identify newer agents that can be effective in the management of MRSA. Appropriate therapy in MRSA is essential to reduce the mortality outcomes. Paul et al. reported significantly higher mortality at day 30 with inappropriate antibiotic therapy $(49.1 \%$ vs. $33.3 \%, \mathrm{p}=0.001)$ in HA-MRSA bacteremia ${ }^{24}$. Thus, newer agents when appropriately used can be effective against the MRSA to improve the outcomes. Table 2 enlists some of the recent anti-MRSA drugs.

$\begin{array}{ll}\begin{array}{l}\text { Table 2: Recent approved and investigational drugs } \\ \text { against MRSA }{ }^{25-32}\end{array} & \text { Drug name } \\ \begin{array}{ll}\text { Group } & \text { Tedizolid, Radezolid and Delpazolid } \\ \text { Oxazolidinedione } & \text { Oritavancin and Dalbavancin } \\ \text { Lipoglycopeptide } & \text { Ceftaroline and Ceftobiprole } \\ \text { Cephalosporins } & \begin{array}{l}\text { Delafloxacin, Levonadifloxacin, Gepoti- } \\ \text { dacin and Lascufloxacin }\end{array} \\ \text { Peptidomimetic } & \text { Brilacidin } \\ \hline\end{array}\end{array}$

Among the various drug in this class, tedizolid is approved for the treatment of acute bacterial skin and skin structure infections (ABSSSI) in adults ${ }^{25}$. Radezolid and Delpazolid are currently under investigation ${ }^{26}$.

Oritavancin and dalbavancin are the lipoglycopeptide antibiotics that are approved for use in ABSSSI in adults. Dalbavancin has potential utility in MDR-MRSA isolates ${ }^{27}$.

Both Ceftaroline and Ceftobiprole offer not only Gram-negative but also Gram-positive coverage and are active against MRSA. Ceftaroline is approved for use in ABSSSI and community-acquired bacterial pneumonia (CABP). Ceftobiprole is active against VISA, and vancomycin-resistant $S$. aureus (VRSA) isolates ${ }^{28,29}$.

Delafloxacin is a quinolone recently approved by the USFDA for the treatment of ABSSSI caused by $\mathrm{MRSA}^{30}$. Levonadifloxacin is a novel, benzoquinolizine subclass of quinolone having potent anti-MRSA activity that was recently approved in India for treatment of ABSSSI caused by MRSA $^{31}$. Lascufloxacin was approved in Japan for respiratory and ENT infections ${ }^{32}$.

Brilacidin is a peptidomimetic antibiotic. It mimics naturally occurring proteins and has strong activity against MDR MRSA isolates. It is under evaluation for use in ABSSSI and serious skin infections ${ }^{26}$.

\section{MRSA infection control and preventive strate- gies}

In a healthcare facility, hand contamination is one of the predominant modes of bacterial pathogen transfer. In taking of patients with MRSA infection, healthcare personnel are at increased risk of harbouring infections. MRSA has been isolated from hands, gloves, aprons, and other instruments that healthcare staff utilized in the care of such patients. Furthermore, MRSA were isolated from the keyboards of com- 
puters used by the doctors ${ }^{33}$. Since MRSA is increasing in incidences at a rapid rate it can be better controlled by understanding its colonization dynamics risk factors for progression of colonization dynamics, routes of transmission, and conditions which enhances the emergence of resistance ${ }^{34}$. For effective control and prevention of MRSA in hospitals, recommended strategies are briefly discussed.

Standard precautions such as hand hygiene should be practiced after examining every patient. The use of gloves is not a replacement for hand washing.

Contact precautions need to be practiced in all patients where MRSA colonization is suspected or confirmed. In asymptomatic patients who serve as MRSA reservoirs, rapid detection tests should be undertaken to identify MRSA to reduce contact transmission.

Active surveillance cultures to identify MRSA carriers at the time of hospital admission (carriers) and periodic screening of admitted patients (cases) need to be undertaken to detect for colonization of MRSA. Studies indicate that without active surveillance, MRSA prevalence can increase gradually in a healthcare setting ${ }^{35,36}$. Nasal swab is the most effective sample with a negative predictive value of $98 \%{ }^{37}$. Besides culture, PCR can be a point of care testing method for the screening of MRSA with the advantage of the lesser time for results ${ }^{38}$. Recent studies identify 7 -fold higher rates of MRSA colonization in hospitalized patients than community population $^{39}$. It indicates the active surveillance of hospitalized patients for MRSA colonization is necessary. Besides patients, active surveillance of HCWs is necessary as they have been identified as carriers of MRSA ${ }^{40-42}$. Surveillance need to be prioritized in HCWs and those working in highrisk areas should be screened. One problem with the screening of HCWs is that majority of them do not have persistent colonization ${ }^{43}$.

Decolonization with topical antimicrobial or antiseptic for suppression and eradication of MRSA from the colonized person is necessary, especially, in persistent MRSA carriers. This will help the establishment of infection in a colonized person, as well as help, prevent the transmission to others. Further research is required to determine the effectiveness of decolonization in reducing MRSA transmission in a hospital setting ${ }^{44}$.

Evidence indicates the disinfection of environmental surfaces and education of the service staff reduces the MRSA contamination ${ }^{45}$.

Controlling the antibiotic use is another strategy to reduce MRSA infection. Controlling antibiotic use helped to reduce the development of antibiotic resistance. Limiting unnecessary and optimizing efficient antibiotic use should be the usual approach. Good antibiotic stewardship can help establish rational antibiotic use. In recent years, better control of
MRSA by involving the number of small molecule potentiators for antibiotics has been proposed. These small molecule potentiators are not actually bactericidal by themselves but function by reversing the resistance mechanisms, interfering with quorum sensing activity, and able to attenuate Staphylococcus aureus virulence ${ }^{46}$.

\section{CONCLUSION}

In a hunt for controlling MRSA, humans have developed a number of diagnoses and preventive techniques but still, MRSA remained dominant in pathogenicity.

Research in the field of diagnosis certainly has reduced the challenge of detection of MRSA and that provides a small window of better treatment by early control of MRSA. With the range of antibiotics such as vancomycin in recent time, new antibiotics therapies also become available which can provide effective alternatives for strains that have acquired resistance to acting drugs. Nevertheless, need always remain alive in terms of vigilance and effective MRSA prevention strategies by regular monitoring and hygiene concepts which will assist in handling the challenge of MRSA with better treatment.

\section{Acknowledgement: None}

Conflict of interest: None

Financial support: None

\section{REFERENCES}

1. Thomer L, Schneewind O, Missiakas DPathogenesis of Staphylococcus aureus Bloodstream Infections. Annual Review of Pathology: 2016 11:1, 343-364

2. Stryjewski ME, Corey GR. Methicillin-resistant staphylococcus aureus: An evolving pathogen. Clin Infect Dis. 2014;58(SUPPL. 1). doi:10.1093/cid/cit613.

3. Indian Network for Surveillance of Antimicrobial Resistance (INSAR) group, India. Methicillin resistant Staphylococcus aureus (MRSA) in India: prevalence \& susceptibility pattern. Indian J Med Res. 2013;137(2):363-369.

4. Vysakh PR, Jeya M. A comparative analysis of community acquired and hospital acquired methicillin resistant Staphylococcus aureus. J Clin Diagn Res. 2013;7(7):1339-1342. doi:10.7860/ JCDR/2013/5302.3139

5. Price JR, Cole K, Bexley A, et al. Transmission of Staphylococcus aureus between health-care workers, the environment, and patients in an intensive care unit: a longitudinal cohort study based on whole-genome sequencing. Lancet Infect Dis. 2017;17(2):207-214. doi:10.1016/S1473-3099(16)30413-3

6. Dulon M, Peters C, Schablon A, Nienhaus A. MRSA carriage among healthcare workers in non-outbreak settings in Europe and the United States: a systematic review. BMC Infect Dis. 2014;14:363. Published 2014 Jul 3. doi:10.1186/1471-2334-14363

7. Shuping LL, Kuonza L, Musekiwa A, Iyaloo S, Perovic O (2017) Hospital-associated methicillin-resistant Staphylococ- 
cus aureus: A cross-sectional analysis of risk factors in South African tertiary public hospitals. PLoS ONE 12(11): e0188216.

8. Mao P, Peng P, Liu Z, Xue Z, Yao C. Risk Factors And Clinical Outcomes Of Hospital-Acquired MRSA Infections In Chongqing, China. Infect Drug Resist. 2019;12:3709-3717. Published 2019 Nov 27. doi:10.2147/IDR.S223536

9. Tiemersma EW, Bronzwaer SL, Lyytikäinen O, Degener JE, Schrijnemakers P, Bruinsma N, Monen J, Witte W, Grundmann H, European Antimicrobial Resistance Surveillance System Participants. Methicillin-resistant Staphylococcus aureus in Europe, 1999-2002. Emerging infectious diseases. 2004 Sep;10(9):1627-34.

10. Kaiser ML, Thompson DJ, Malinoski D, Lane C, Cinat ME. Epidemiology and risk factors for hospital-acquired methicillin-resistant Staphylococcus aureus among burn patients. J Burn Care Res. 2011;32(3):429-434. doi:10.1097/BCR.0b013e318217f92d

11. Madani TA. Epidemiology and clinical features of methicillinresistant Staphylococcus aureusin the University Hospital, Jeddah, Saudi Arabia. Can J Infect Dis 2002;13(4):245-25

12. Hussein N, Salih R S, Rasheed N A. Prevalence of MethicillinResistant Staphylococcus aureus in Hospitals and Community in Duhok, Kurdistan Region of Iraq, Int J Infect. Online ahead of Print ; 6(2):e89636. doi: 10.5812/iji.89636.

13. McKinnell JA, Miller LG, Eells SJ, Cui E, Huang SS. A systematic literature review and meta-analysis of factors associated with methicillin-resistant Staphylococcus aureus colonization at time of hospital or intensive care unit admission. Infect Control Hosp Epidemiol. 2013;34(10):1077-1086. doi:10.1086/673157

14. Brown DF, Edwards DI, Hawkey PM, Morrison D, Ridgway GL, Towner KJ, Wren MW. Guidelines for the laboratory diagnosis and susceptibility testing of methicillin-resistant Staphylococcus aureus (MRSA). Journal of Antimicrobial chemotherapy. 2005 Dec 1;56(6):1000-18.

15. Harbarth S, Hawkey PM, Tenover F, Stefani S, Pantosti A, Struelens MJ. Update on screening and clinical diagnosis of meticillin-resistant Staphylococcus aureus (MRSA). Int J Antimicrob Agents. 2011;37(2):110-117. doi:10.1016/j.ijantimicag.2010.10.022

16. Marlowe EM, Bankowski MJ. Conventional and Molecular Methods for the Detection of Methicillin-Resistant Staphylococcus aureus. J Clin Microbiol. 2011;49(9 Suppl):S53-S56. doi:10.1128/JCM.00791-11

17. Pourmand MR, Hassanzadeh S, Mashhadi R, Askari E. Comparison of four diagnostic methods for detection of methicillin resistant Staphylococcus aureus. Iran J Microbiol. 2014;6(5):341344.

18. El-Baz R, Rizk DE, Barwa R, Hassan R. Virulence characteristics and molecularrelatedness of methicillin resistant Staphylococcus aureus harboring differentstaphylococcal cassette chromosome mec. Microb Pathog. 2017 ;113:385-395

19. Boucher H, Miller LG, Razonable RR. Serious Infections Caused by Methicillin-Resistant Staphylococcus aureus. Clinical Infectious Diseases. 2010; 51(S2):S183-S197.

20. Chatterjee A, Rai S, Guddattu V, Mukhopadhyay C, Saravu K. Is methicillin-resistant Staphylococcus Aureus infection associated with higher mortality and morbidity in hospitalized patients? A cohort study of 551 patients from South Western India. Risk management and healthcare policy. 2018;11:243.

21. Liu C, Bayer A, Cosgrove SE, et al. Clinical practice guidelines by the infectious diseases society of america for the treatment of methicillin-resistant Staphylococcus aureus infections in adults and children. Clin Infect Dis. 2011;52(3):e18-e55. doi:10.1093/ $\mathrm{cid} / \mathrm{ciq} 146$
22. Kumar M. Multidrug-Resistant Staphylococcus aureus, India, 2013-2015. Emerging Infectious Diseases. 2016;22(9):16661667. doi:10.3201/eid2209.160044.

23. Kashyap R, Shah A, Dutt T, Wieruszewski PM, Ahdal J, Jain R. Treatments and limitations for methicillin-resistant Staphylococcus aureus: A review of current literature. World J Clin Infect Dis 2019; 9(1): 1-10.

24. Paul M, Kariv G, Goldberg E, Raskin M, Shaked H, Hazzan R, Samra Z, Paghis D, Bishara J, Leibovici L. Importance of appropriate empirical antibiotic therapy for methicillin-resistant Staphylococcus aureus bacteraemia. Journal of Antimicrobial Chemotherapy. 2010 Oct 14;65(12):2658-65.

25. SIVEXTRO (Tedizolid phsophate) Highlights of the prescribing information. Intial US approval 2014. Available from https://www.accessdata.fda.gov/drugsatfda_docs/ label/2019/205436s005lbl.pdf

26. Vuong C, Yeh AJ, Cheung GY, Otto M. Investigational drugs to treat methicillin-resistant Staphylococcus aureus. Expert opinion on investigational drugs. 2016 Jan 2;25(1):73-93.

27. Sader HS, Mendes RE, Duncan LR, Pfaller MA, Flamm RK. Antimicrobial activity of dalbavancin against Staphylococcus aureus with decreased susceptibility to glycopeptides, daptomycin, and/or linezolid from US medical centers. Antimicrobial agents and chemotherapy. 2018 Mar 1;62(3):e02397-17.

28. TEFLARO (Ceftarolinefosamil) Highlights of the prescribing information. Initial US approval 2011. Available from https://www. accessdata.fda.gov/drugsatfda_docs/label/2010/200327s000lbl. pdf

29. Pfaller MA, Flamm RK, Mendes RE, StreitJM, Smart JI, Hamed KA, Duncan LR, Sader HS.2019. Ceftobiprole activity against Gram-positiveand -negative pathogens collected from theUnited States in 2006 and 2016. Antimicrob Agents Chemother 63:e01566-18.https://doi.org/10.1128/AAC.01566-18.

30. BAXDELA (Delafloxacin) Highlights of the prescribing information. Intial US approval 2017. Available from https://www. accessdata.fda.gov/drugsatfda_docs/label/2017/208610s000,20 8611s000lbl.pdf

31. Alalevonadifloxacin mesylate bulk and Levonadifloxacin tablets $500 \mathrm{mg}$ https://cdsco.gov.in/opencms/resources/UploadCDSCOWeb/2018/UploadApprovalNewDrugs/newdrugapprovaldec3119.pdf

32. Kyorin Pharmaceutical Receives Marketing Approval for Oral Quinolone Antibacterial Agent "Lasvic ${ }^{\circledR}$ Tablets $75 \mathrm{mg}$ " https:// www.kyorin-pharm.co.jp/en/news/691640e4c4142c191c8d406 1a71c02e299076a4a.pdf

33. Alvarez C, Labarca J, Salles M. Prevention strategies for methicillin-resistant Staphylococcus aureus (MRSA) in Latin America. Brazilian Journal of Infectious Diseases. 2010 Dec;14:107-8.

34. Calfee DP, Salgado CD, Milstone AM, Harris AD, Kuhar DT, Moody J, et al. Strategies to prevent methicillin-resistant Staphylococcus aureus transmission and infection in acute care hospitals: 2014 update. Infect Control Hospital Epidemiol. 2014;35:772-96.

35. Wernitz MH, Swidsinski S, Weist $\mathrm{K}$ et al. Effectiveness of a hospital-wide selective screening programme for methicillin resistant Staphylococcus aureus (MRSA) carriers at hospital admission to prevent hospital-acquired MRSA infections. Clin Microbiol Infect. 2005; 11(6):457-65.

36. Tomic V, SvetinaSorli P, Trinkaus D et al. Comprehensive strategy to prevent nosocomial spread of methicillin-resistant Staphylococcus aureus in a highly endemic setting. Arch Intern Med. 2004; 164(18):2038-43.

37. Manian FA, Senkel D, Zack J, Meyer L. Routine screening for methicillin-resistant Staphylococcus aureus among patients 
newly admitted to an acute rehabilitation unit. Infect Control Hosp Epidemiol. 2002; 23(9):516-9.

38. Brenwald NP, Baker N, Oppenheim B. Feasibility study of a real-time PCR test for meticillin-resistant Staphylococcus aureus in a point of care setting. J Hosp Infect. 2009; 74(3):245-9.

39. Manthreshwar P, Sekar R, Narendran S, Amudhan M, Mythreyee M. Higher rate of methicillin-resistant Staphylococcus aureus carriage amongst hospitalised patients in rural South India. J Patient Saf Infect Control 2017;5:30-4

40. Mathanraj S, Sujatha S, Sivasangeetha K, Parija S C. Screening for methicillin-resistant Staphylococcus aureus carriers among patients and health care workers of a tertiary care hospital in south India. Indian J Med Microbiol2009;27:62-4.

41. M Radhakrishna, D’Souza M, Kotigadde S, Saralaya K V, Kotian M S. Prevalence of Methicillin Resistant Staphylococcus aureus Carriage amongst Health Care Workers of Critical Care Units in Kasturba Medical College Hospital, Mangalore, India. J Clin Diagn Res. 2013 Dec;7(12):2697-700.

42. Schubert M, Kämpf D, Jatzwauk L, Kynast F, Stein A, Strasser R, Dulon M, Nienhaus A, Seidler A. Prevalence and predictors of MRSA carriage among employees in a non-outbreak setting: A cross-sectional study in an acute care hospital. Journal of Occupational Medicine and Toxicology. 2019 Dec;14(1):7.

43. Vonberg RP, Stamm-Balderjahn S, Hansen S et al. How often do asymptomatic healthcare workers cause methicillin-resistant Staphylococcus aureus outbreaks? A systematic evaluation. Infect Control Hosp Epidemiol. 2006; 27(10):1123-7.

44. Humphreys H. Can we do better in controlling and preventing methicillin-resistant Staphylococcus aureus (MRSA) in the intensive care unit (ICU)? Eur J Clin Microbiol Infect Dis. 2008; 27(6):409-13.

45. Goodman ER, Platt R, Bass R et al. Impact of an environmental cleaning intervention on the presence of methicillin-resistant Staphylococcus aureus and vancomycin-resistant enterococci on surfaces in intensive care unit rooms. Infect Control Hosp Epidemiol. 2008; 29(7):593-9.

46. Vermote A, Van Calenbergh S. Small-molecule potentiators for conventional antibiotics against Staphylococcus aureus. ACS infectious diseases. 2017 Nov 10;3(11):780-96. 